\title{
Relative dormancy in excised vegetative buds of Rhododendron
}

\author{
R. L. M. Pierik \\ Department of Horticulture, Agricultural University, P.O. Box 30, Wageningen, \\ the Netherlands
}

Accepted: 3 December 1975

Key words: bud dormancy, Rhododendron, adventitious roots, vegetative buds, in vitro

\section{Summary}

Excised vegetative buds of Rhododendron 'Pink Pearl', present in the axils of the bud scales, require light for sprouting, but no special daylength is necessary to break dormancy. Glucose greatly enhances sprouting but is not absolutely required. Glucose cannot replace light, but light can partly replace glucose. Only fully developed buds are capable of sprouting. Temperature plays a decisive role in sprouting, 21-25 ${ }^{\circ} \mathrm{C}$ being the optimum range. Macroelements are not essential, but sprouting on a medium without macroelements is reduced. It was impossible to induce adventitious root formation on excised shoots, grown on medium containing IBA.

\section{Introduction}

In previous experiments on adventitious root formation of isolated stem segments of Rhododendron (Pierik, 1969; Pierik \& Steegmans, 1975), it occasionally happened that vegetative buds in the axils of bud scales developed into shoots. This phenomenon excited our interest since vegetative propagation of Rhododendron through excised bud culture and rooting of excised buds might be important for the rapid introduction of a new cultivar. For that reason an investigation was carried out to determine the limiting factors for sprouting of Rhododendron buds in vitro. The in vitro system was chosen since small buds could not be grown in vivo and because the in vitro environment could be controlled at will.

During the study two papers (Schneider, 1968, 1970) appeared in which the rest period of Rhododendron flower buds in situ and in vitro was described. For reasons mentioned above and because Schneider's results with generative buds do not agree at all with the experiments with vegetative buds, a short description of the work is given in this paper.

1 Publication 424. Department of Horticulture, Agricultural University, Wageningen, the Netherlands. 


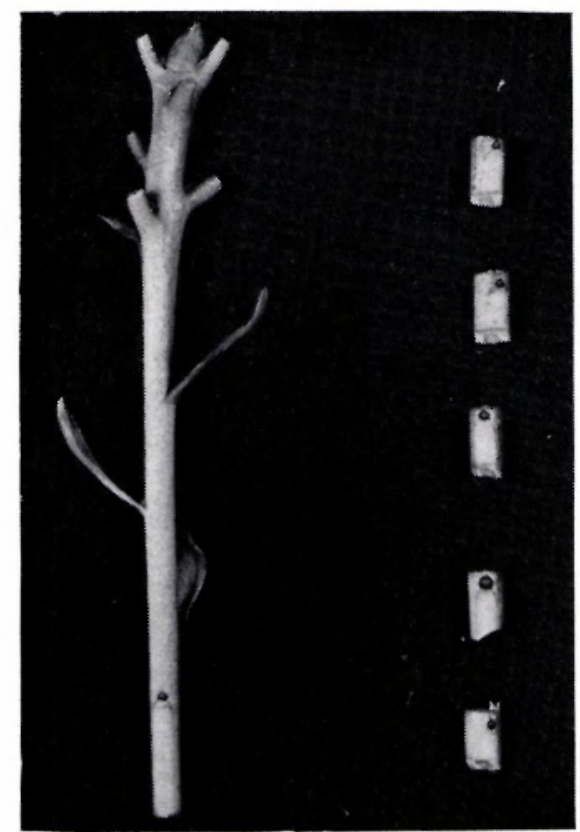

Fig. 1. Left: Rhododendron shoot before sterilization. Dormant buds in the axils of the bud scales.

Right: Explants after sterilization. Each stem section has a small dormant bud.

\section{Material and methods}

Stems of Rhododendron 'Pink Pearl' were selected from plants grown in a greenhouse as previously described (Pierik \& Steegmans, 1975). Stems were collected 4-6 weeks after the sprouting of the terminal buds and sterilized as described earlier (Pierik \& Steegmans, 1975). The small fully developed vegetative buds in the axils of the bud scales were still in a 'dormant' condition and 1-2 mm in diameter. Fig. 1 illustrates the bud-stem explants before sterilization (left) and after excision (right). Each stem segment containing one 'dormant' bud in the middle was placed with the basal end down on a solid culture medium with the following composition (unless stated otherwise): Knop's (1884) macroelements, Heller's (1953) microelements (except $\mathrm{FeCl}_{3}$ ), NaFeEDTA $25 \mathrm{mg} / \mathrm{l}$, glucose $3 \%$, Difco Bacto-agar $0.6 \%$ and pyrex-distilled water. The $\mathrm{pH}$ was adjusted to 6.0 before autoclaving. Unless otherwise stated, cultures were kept at $23^{\circ} \mathrm{C}$ in continuous fluorescent light (Philips TL $57 / 40 \mathrm{~W}$ ) with an irradiance of $14 \mathrm{~W} \mathrm{~m}^{-2}$. In most experiments observations on shoot development were terminated after 28 to 32 days.

The objective of these experiments has been to examine the effect of one factor on relative dormancy (Vegis, 1973) while keeping the others (see above) constant. The choice of the standard growth conditions was based on several preliminary experiments. The percentage of bud sprouting indicates the percentage of non-infected segments forming a shoot. There were 24 stem explants per treatment. 


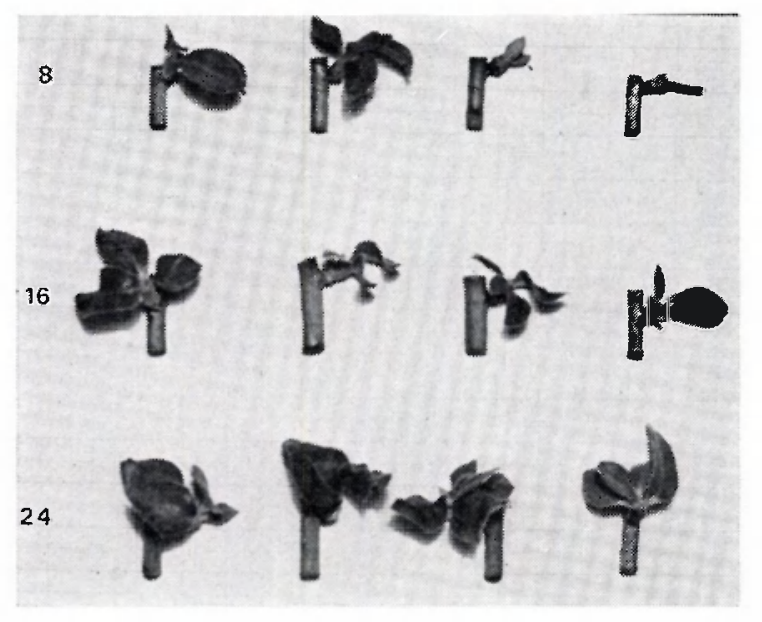

Fig. 2. The influence of daylength $(8,16$ and $24 \mathrm{~h})$ on rest breaking and subsequent growth of sprouts.

\section{Results}

Since the mother plants were grown under long-day conditions, it was expected that excised buds were not in a true dormant condition. The results, therefore, do not refer to rest breaking but only to the development of buds into sprouts (breaking of relative dormancy) under controlled environmental conditions. One of the most essential prerequisites for bud sprouting appeared to be the size of the bud; young buds which develop after the sprouting of the terminal bud, did not respond to any treatment; only older fully developed buds were capable of growing into a leafy shoot without roots. The position of the bud on the stem had no effect.

The influence of the daylength is presented in Table $1 \mathrm{~A}$ which shows that the percentage of bud sprouting slightly increased with an increase in the daylength; at the end of the experiment a difference in bud sprouting and growth remained visible between the treatments 8,16 and $24 \mathrm{~h}$ (Fig. 2). However, sprouting in continuous darkness was impossible. Table $1 \mathrm{~B}$ shows the results obtained when stem explants were grown at various light intensities. Sprout formation was promoted when light intensity was increased from 6.1 to $26.6 \mathrm{~W} \mathrm{~m}^{-2}$, while there was again a complete inhibition of sprouting in darkness.

The role of the sugar concentration is shown in Table 1C. Bud sprouting was greatly increased when the glucose concentration was raised from 0.0 to $3.0 \%$. However, the sprouting declined for the 3.0 to $9.0 \%$ glucose concentration range. The optimum range was observed to be 1.5 to $3.0 \%$.

The effect of temperature was examined in a phytotron (Doorenbos, 1964). Table 1D shows that sprouting was strongly enhanced when the temperature was raised from 9 to $25^{\circ} \mathrm{C}$. See also Fig. 3 .

Table 1E shows that during the first 24 days after excision, bud sprouting was poor on the medium without macroelements (Fig. 4); a marked difference between 


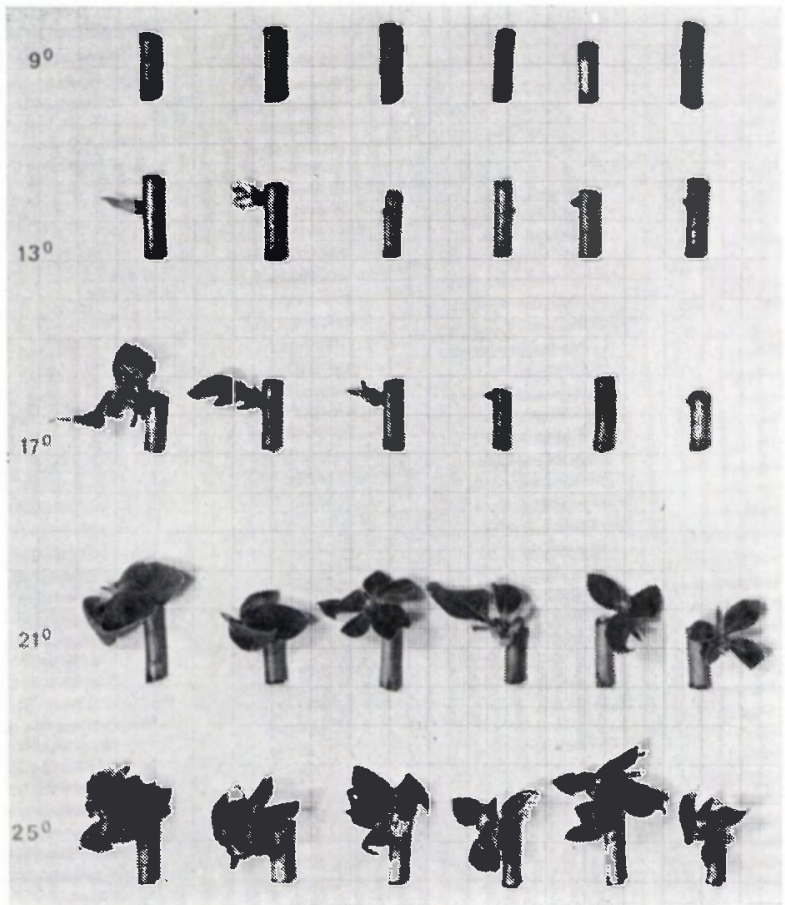

Fig. 3. The effect of temperature on in vitro cultivated Rhododendron stem explants.

Knop's macroelements at half and at full strength was not found, although buds grew poorly on a medium lacking macroelements (Fig. 4).

Several experiments were carried out to induce adventitious root formation on the basal ends of excised sprouts on a medium containing IBA at $5 \cdot 10^{-7}$ or $5 \cdot 10^{-6}$

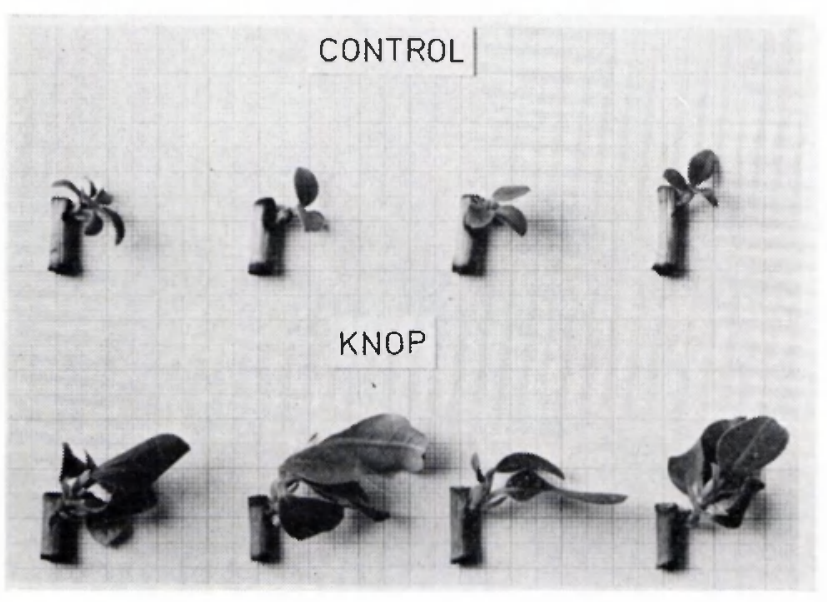

Neth. J. agric. Sci. 24 (1976)
Fig. 4. The influence of the composition of the medium on bud growth.

Upper row: no macroelements. Lower row: Knop's macroelements at full strength. 
Table 1. The influence of various factors on the percentage of bud sprouting in excised stem explants of Rhododendron 'Pink Pearl', each containing a stem section with one small dormant vegetative bud.

$\overline{\text { Treatment }} \quad \frac{\% \text { bud sprouting ... days after excision }}{24}$

A. Daylength $(h)$

$\begin{array}{rrrr}0 & 0 & 0 & 0 \\ 8 & 23 & 67 & 91 \\ 16 & 33 & 67 & 95 \\ 24 & 42 & 79 & 100\end{array}$

B. Light intensity $\left(\mathrm{Wm}^{-2}\right)$

$\begin{array}{rrrr}0 & 0 & 0 & 0 \\ 6.1 & 0 & 27 & 81 \\ 14.0 & 0 & 31 & 69 \\ 20.3 & 0 & 57 & 67 \\ 26.6 & 19 & 62 & 86\end{array}$

C. Glucose concentration (\%)

$\begin{array}{lrrr}0 & 14 & 25 & 29 \\ 1.5 & 25 & 50 & 83 \\ 3.0 & 21 & 66 & 73 \\ 4.5 & 5 & 42 & 42 \\ 6.0 & 4 & 25 & 57 \\ 7.5 & 0 & 12 & 35 \\ 9.0 & 0 & 0 & 21\end{array}$

D. Temperature $\left({ }^{\circ} \mathrm{C}\right)$

$\begin{array}{rrrr}9 & 0 & 0 & 0 \\ 13 & 0 & 0 & 13 \\ 17 & 0 & 14 & 37 \\ 21 & 4 & 36 & 70 \\ 25 & 10 & 85 & 95\end{array}$

E. Knop's macroelements (strength)

\begin{tabular}{llll}
0 & 7 & 27 & 80 \\
0.5 & 7 & 46 & 77 \\
1.0 & 5 & 53 & 75 \\
\hline
\end{tabular}

$\mathrm{g} / \mathrm{ml}$. Neither young, soft shoots ( 15 days old) nor older shoots ( 30 days old) were capable of regenerating roots at $23{ }^{\circ} \mathrm{C}$ in continuous light. From 80 excised shoots, 40 young and 40 old, only one regenerated adventitious roots. Even when the sprouts were grown in light and the basal end of the cutting in darkness, no root regeneration took place.

\section{Discussion and conclusions}

This study has shown that sprouting requires light, although no special daylength 
is required, because $8 \mathrm{~h}$ of light per day already induced sprouting. This observation is partly (i.e. with regard to the light requirement) in agreement with the reaction of Fagus, Betula and Quercus (cf. Vegis, 1973) and partly (i.e. with regard to the daylength) not. The promotion of sprouting by increasing daylength or light intensity can be simply explained by a promotion of photosynthesis; this explanation is supported by the observation that glucose promotes sprouting.

It can also be concluded that glucose can only partly be replaced by light and that light cannot be replaced by glucose. The fact that growth of excised buds has never (except in Fagus) been observed to occur in complete darkness (Wareing, 1953 ) is in agreement with our observations.

The role of temperature as well as mineral nutrition is clear. Sprouting is accelerated by a raise of the temperature and by applying macroelements according to Knop at half or at full strength. Vegis (1973) reported that at present only a few species (e.g. potato) are known in which resting buds retain for a long time the inability to develop into a sprout except at higher temperatures. It is clear that Rhododendron is another example; in this species the small vegetative buds in the axils of the bud scales remain in a relative dormant state until temperature is high enough for them to develop into a leafy shoot.

Schneider $(1968,1970)$ has given a detailed description of the rest period of Rhododendron flower buds in situ and in vitro. He showed that the onset and the duration of rest depended upon the presence of the flower bud scales; when the scales were removed before the onset of rest, the flowers continue to elongate, but intact buds with scales stopped growing and remained in rest for at least four months; thus, scale removal after the onset of rest terminated the rest period. Schneider's results with flower buds differ from our findings on rest breaking of vegetative Rhododendron buds. The only conclusion that can be drawn is that the breaking of rest of vegetative buds is completely different from generative buds.

The culture medium used by Schneider $(1968,1970)$ contained $15 \%$ sucrose and $0.7 \%$ agar. It is amazing that Schneider could obtain flower bud development with such a high sucrose concentration in the medium (see Table 1C). It is also strange that he did not prepare a 'normal' medium containing macro- and microelements and a 'normal' sugar concentration, although in his last two experiments (Schneider, 1970 ) he added minerals. Schneider's conclusion that the rest period of generative Rhododendron buds was not affected by temperature or by the addition of minerals does not agree with the results described in this paper (Table 1D and 1E). It should be concluded again that vegetative and generative buds behave in a different way. However, it is not impossible that Schneider's interpretation of his results is wrong because a sucrose concentration of $15 \%$ can partly inhibit bud growth under the conditions used. Schneider showed that in vitro culture of excised vegetative or generative buds can be an interesting tool for studying dormancy under completely controlled environmental conditions with a simple model: the excised bud or a stem explant containing a bud. He concluded that tissue culture experiments are encouraging but that this system has some limitations as he was unable to select buds that have the same resting status. However, our experiments with small uniform buds from the axils of the bud scales show that this is perfectly feasable. 
A disappointing result of our study has been that excised Rhododendron shoots could not be induced to form adventitious roots. In earlier work (Pierik \& Steegmans, 1975), we came to the same conclusion. The explanation offered, viz bad ozygen supply at the basal end of the cutting in the agar medium, seems reasonable but has not yet been proved.

\section{Acknowledgments}

The author is grateful to the Experimental Station for Arboriculture, Boskoop, the Netherlands, for providing the Rhododendron plants. He gratefully acknowledges the help of the following persons during part of this investigation: Mrs H. M. S. Ebbens-Groot, Mrs C. Mast-Kruiniger, Mrs J. C. Joosse-de Jong, Mr W. van Schaik and Mr S. Roest.

\section{References}

Doorenbos, J., 1964. Het fytotron van het Laboratorium voor Tuinbouwplantenteelt. Meded. Dir. Tuinb. 27: $432-437$ (in Dutch).

Heller, R., 1953. Récherches sur la nutrition minérale des tissus végétaux cultivés in vitro. Annls Sci. nat. Bot. Biol. vég. 14: 1-223.

Knop, W., 1884. Bereitung einer konzentrierter Nährstofflösung für Pflanzen. Mitt. Landw. Versinth 30: 292-294.

Pierik, R. L. M., 1969. Factors affecting adventitious root formation in isolated stem segments of Rhododendron. Neth. J. agric. Sci. 17: 203-208.

Pierik, R. L. M. \& H. H. M. Steegmans, 1975. Analysis of adventitious root formation in isolated stem explants of Rhododendron. Scientia Hort. 3: 1-20.

Schneider, E. F., 1968. The rest period of Rhododendron flower buds. I. Effect of the bud scales on the onset and duration of rest. J. exp. Bot. 19: 817-824.

Schneider, E. F., 1970. The rest period of Rhododendron flower buds. II. Studies on the rest period in tissue culture and in situ. J. exp. Bot. 21: 799-807.

Vegis, A., 1973. Dependence of the growth processes on temperature. In: Temperature and life. Springer Verlag, Berlin, pp. 145-170.

Wareing, P. F., 1953. Growth studies in woody species. V. Photoperiodism in dormant buds of Fagus sylvatica L. Physiologia Pl. 6: 692-706. 